\title{
PENGARUH NET PROFIT MARGIN, EARNING PER SHARE, DAN RETURN ON ASSET TERHADAP HARGA SAHAM PERUSAHAAN PROPERTI DI BEI
}

\author{
Kenny \\ Program Studi Magister Manajemen Universitas Tarumanagara \\ kennytandri@yahoo.co.id
}

\begin{abstract}
This study aims to analyze factors that affect the stock price of property companies that are listed in BEI within a period between year 2012 to 2016. This research is a study to determine the influence between net profit margin, earning per share, and return asset towards stock price. The population used in this research are all property companies that are listed in BEI during the research period. The samples are collected by using the purposive sampling method. There are 17 companies that are used as samples for this research. This research used multiple linear regression, with t-statistic test, F-statistic test, and adjusted coefficient of determination to determine the truth about hypotheses. The result of this research are net profit margin has negative and significant effect on the stock price, while earning per share and return on asset has non-significant effect on the stock price. Together, Net Profit Margin, Earning Per Share, and Return On Asset have significant effect on stock price.
\end{abstract}

Abstrak: Penelitian ini bertujuan untuk menganalisa faktor-faktor yang mempengaruhi harga saham perusahaan properti yang terdaftar di BEI dalam periode tahun 2012 hingga 2016. Penelitian ini digunakan untuk mengetahui pengaruh antara net profit margin, earning per share, dan return on asset terhadap harga saham perusahaan properti. Populasi dalam penelitian ini merupakan seluruh perusahaan properti yang terdapat di BEI selama periode penelitian. Sampel dikumpulkan dengan menggunakan teknik purposive sampling. Terdapat 17 persuaahaan yang digunakan sebagai sampel dalam penelitian ini. Penelitian ini menggunakan regresi linear berganda, dengan uji-t, uji-F, dan koefisien determinasi untuk menentukan kebenaran dari hipotesis. Hasil dari penelitian ini adalah net profit margin memiliki pengaruh negatif signifikan terhadap harga saham, earning per share dan return on asset memiliki pengaruh tidak signifikan terhadap harga saham. Secara bersama-sama, net profit margin, earning per share, dan return on asset memiliki pengaruh signifikan terhadap harga saham.

Keywords: net profit margin, earning per share, return on asset, stock price, property.

\section{LATAR BELAKANG}

Sektor properti merupakan salah satu sektor yang memiliki peran penting untuk meningkatkan pertumbuhan ekonomi Indonesia. Prihantini (2009) berpendapat bahwa penyebab banyaknya masyarakat yang menginvestasikan modalnya di industri properti dikarenakan harga tanah yang cenderung naik, yang disebabkan oleh supply tanah yang bersifat tetap sedangkan demand tanah akan selalu besar seiring dengan pertambahan penduduk.

Untuk menghindari risiko kerugian, investor harus melakukan berbagai analisis terlebih dahulu sebelum melakukan investasi, termasuk analisis laporan keuangan. Salah satu alat yang dapat digunakan oleh investor dalam melakukan analisa laporan keuangan tersebut adalah dengan menggunakan rasio keuangan.

Terdapat berbagai jenis rasio keuangan yang dapat dianalisis oleh investor. Junita dan Khairani (2013) mengungkapkan bahwa rasio keuangan digunakan untuk mengevaluasi 
kondisi dan kinerja keuangan. Beberapa rasio yang dapat digunakan untuk mengevaluasi kinerja tersebut adalah net profit margin, earning per share, dan return on asset.

Berdasarkan latar belakang diatas, maka peneliti tertarik untuk melakukan penelitian mengenai "Pengaruh Net Profit Margin, Earning Per Share, dan Return On Asset Terhadap Harga Saham Perusahaan Properti di Bursa Efek Indonesia”.

\section{Tujuan Penelitian}

Tujuan dilakukannya penelitian ini adalah sebagai berikut:

- Untuk mengkaji apakah terdapat pengaruh antara Net Profit Margin (NPM) terhadap harga saham perusahaan properti yang terdaftar di BEI.

- Untuk mengkaji apakah terdapat pengaruh antara Earning Per Share (EPS) terhadap harga saham perusahaan properti yang terdaftar di BEI.

- Untuk mengkaji apakah terdapat pengaruh antara Return On Asset (ROA) terhadap harga saham perusahaan properti yang terdaftar di BEI.

- Untuk mengkaji apakah terdapat pengaruh secara bersama-sama antara Net Profit Margin (NPM), Earning Per Share (EPS), dan Return On Asset (ROA) terhadap harga saham perusahaan properti yang terdaftar di BEI.

\section{TINJAUAN PUSTAKA}

- Saham

Aulianisa (2012) menyatakan bahwa saham merupakan surat berharga keuangan yang diterbitkan oleh suatu perusahaan sebagai salah satu alat untuk meningkatkan modal panjang.

Nilai dari suatu saham tercermin dari harga saham tersebut. Menurut Novitasari (2013), harga saham terbentuk oleh supply dan demand atas saham tersebut.

- Net Profit Margin (NPM)

Net Profit Margin (NPM) merupakan salah satu rasio yang digunakan untuk mengukur profitabilitas perusahaan. Jaenudin (2012) menyatakan bahwa rasio ini mencerminkan efektivitas biaya dari kegiatan perusahaan. Titman, Keown, dan Martin (2011) menjelaskan bahwa net Profit margin (NPM) suatu perusahaan dapat dihitung dengan rumus sebagai berikut :

\section{- Earning Per Share (EPS)}

$$
\mathrm{NPM}=\frac{\text { Net Income }}{\text { Sales }}
$$

Earning per share (EPS) merupakan salah satu rasio yang dapat digunakan sebagai alat ukur profitabilitas suatu perusahaan. Putri dan Sampurno (2012) menyebutkan bahwa earning per share (EPS) adalah keuntungan perusahaan yang bisa dibagikan kepada pemegang saham. Rasio earning per share (EPS) dapat dirumuskan sebagai berikut (Soedijono,1993, dikutip oleh Putri dan Sampurno, 2012):

- Return On Asset (ROA)

$$
\text { EPS }=\frac{\text { Net Profit After Tax }}{\text { Outstanding Shares }}
$$

Return on Asset (ROA) merupakan salah satu rasio profitabilitas. Jaenudin (2012) berpendapat bahwa return on asset (ROA) dapat digunakan untuk menilai apakah perusahaan efisien dalam memanfaatkan kegiatan operasional perusahaan. Menurut Darmawansyach (2012), return on asset (ROA) dapat dirumuskan sebagai berikut :

$$
\mathrm{ROA}=\frac{\text { Net Income After Tax }}{\text { Total Asset }}
$$




\section{Hipotesis Pemikiran}

Berdasarkan teori yang telah diuraikan di atas, maka akan diuji apakah variabel net profit margin (NPM), earning per share (EPS), dan return on asset (ROA) berpengaruh terhadap harga saham perusahaan properti yang terdaftar di BEI. Metode penelitian dalam penelitian ini adalah sebagai berikut:

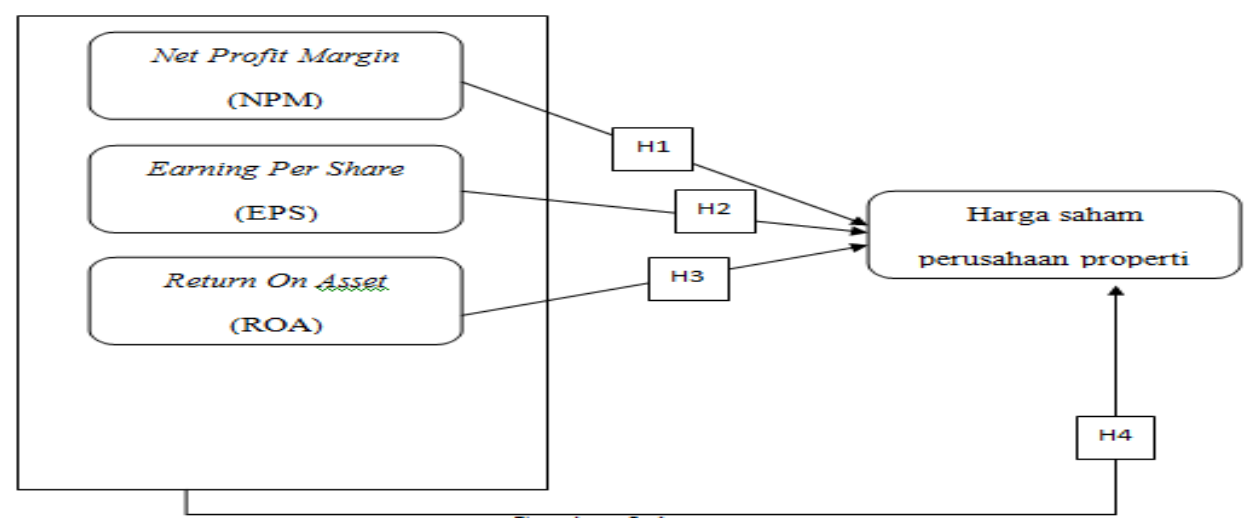

Dalam penelitian ini terdapat empat hipotesis yang diuji, yaitu :

- H1: Terdapat pengaruh signifikan antara net profit margin (NPM) dengan harga saham perusahaan properti.

- H2: Terdapat pengaruh signifikan antara earning per share (EPS) terhadap harga saham perusahaan properti.

- H3: Terdapat pengaruh signifikan antara return on asset (ROA) terhadapharga saham perusahaan properti.

- H4: Terdapat pengaruh signifikan antara net profit margin (NPM), earning per share (EPS), return on asset (ROA) dan return on equity (ROE) terhadap harga saham perusahaan properti.

\section{METODOLOGI PENELITIAN}

Jenis data yang digunakan dalam penelitian ini adalah data sekunder, yaitu harga saham, net profit margin (NPM), earning per share (EPS), dan return on asset (ROA). Sumber data diperoleh dari website perusahaan, www.financeyahoo.com, dan www.investing.com. Populasi penelitian ini adalah perusahaan properti yang terdaftar di BEI untuk tahun 2012, 2013, 2014, 2015, dan 2016. Sampel dipilih secara purposive sampling dengan kriteria sebagai berikut: 1. Perusahaan-perusahaan properti real estate yang terdaftar di Bursa Efek Indonesia (BEI) tahun 2012-2016. 2. Telah mempublikasikan laporan keuangan dalam mata uang Rupiah di tahun 2012-2016. 3. Memiliki informasi keuangan dan harga saham yang lengkap. 4. Telah membukukan laba pada tahun 2012-2016.Berdasarkan kriteria pemilihan sampel di atas, diperoleh sejumlah 17 perusahaan properti yang memenuhi syarat penelitian untuk dijadikan sampel.

Sebelum dilakukan analisis, data yang telah dikumpulkan diuji terlebih dahulu dengan uji asumsi klasik agar mendapatkan hasil yang lebih efisien. Penelitian ini menggunakan uji regresi berganda untuk mengetahui hubungan variabel dependen terhadap beberapa variabel independen. Pengujian hipotesis dalam penelitian ini dilakukan dengan beberapa cara, yaitu: 1. Uji-t, 2. Uji-F, dan 3. Koefisien Determinasi (R2). Sebelum dilakukan uji statistik, data diubah kedalam fungsi log terlebih dahulu. Hal ini dilakukan karena data penelitian ini tidak terdistribusi secara normal sehingga data tersebut harus ditransformasi terlebih dahulu

\section{Hasil Penelitian}

Sebelum dilakukan analisis, data yang telah dikumpulkan harus diuji terlebih dahulu agar mendapat hasil yang lebih efisien.

- Uji Multikolinearitas 


\begin{tabular}{c|lll}
\multicolumn{1}{c}{} & \multicolumn{1}{c}{ LNPM } & \multicolumn{1}{c}{ LEPS } & \multicolumn{1}{c}{ LROA } \\
\cline { 2 - 4 } LNPM & 1 & 0,435866975 & 0,687536475 \\
LEPS & 0,435866975 & 1 & 0,778676907 \\
LROA & 0,687536475 & 0,778676907 & 1
\end{tabular}

Berdasarkan tabel diatas, variabel NPM, EPS, dan ROA memiliki nilai lebih kecil dari 0,8. Artinya, dengan tingkat keyakinan $95 \%$, tidak terdapat multikolinearitas pada data Net Profit Margin (NPM), Earning Per Share (EPS), dan Return On Asset (ROA).

- Uji Autokorelasi

\begin{tabular}{|c|r|}
\hline Durbin-Watson stat & 1.853452 \\
\hline
\end{tabular}

Dari hasil tabel di atas, dapat disimpulkan bahwa besarnya nilai statistik DurbinWatson adalah 1,853452. Dengan jumlah variabel (k) sebesar tiga dan jumlah observasi (n) sebanyak 85. Hal ini menjadikan $\mathrm{dU}<\mathrm{DW}<4$-dU sehingga dapat ditarik kesimpulan bahwa dengan tingkat keyakinan $95 \%$ tidak terdapat autokorelasi.

- Uji Heteroskedastisitas

\begin{tabular}{crrrr}
\hline \hline Variable & Coefficient & Std. Error & t-Statistic & Prob. \\
\hline \hline C & 0.135042 & 0.328118 & 0.411566 & 0.6820 \\
LNPM & 0.108034 & 0.148353 & 0.728228 & 0.4691 \\
LEPS & -0.009548 & 0.114657 & -0.083271 & 0.9339 \\
LROA & -0.076125 & 0.135442 & -0.562048 & 0.5760 \\
\hline \hline
\end{tabular}

Uji Heteroskedastisitas menggunakan uji Geyser. Hasil probabilitas masing-masing variabel > 0.05. Hal ini menunjukkan bahwa dengan tingkat keyakinan $95 \%$ tidak terdapat hasil heteroskedastisitas.

- Uji Normalitas

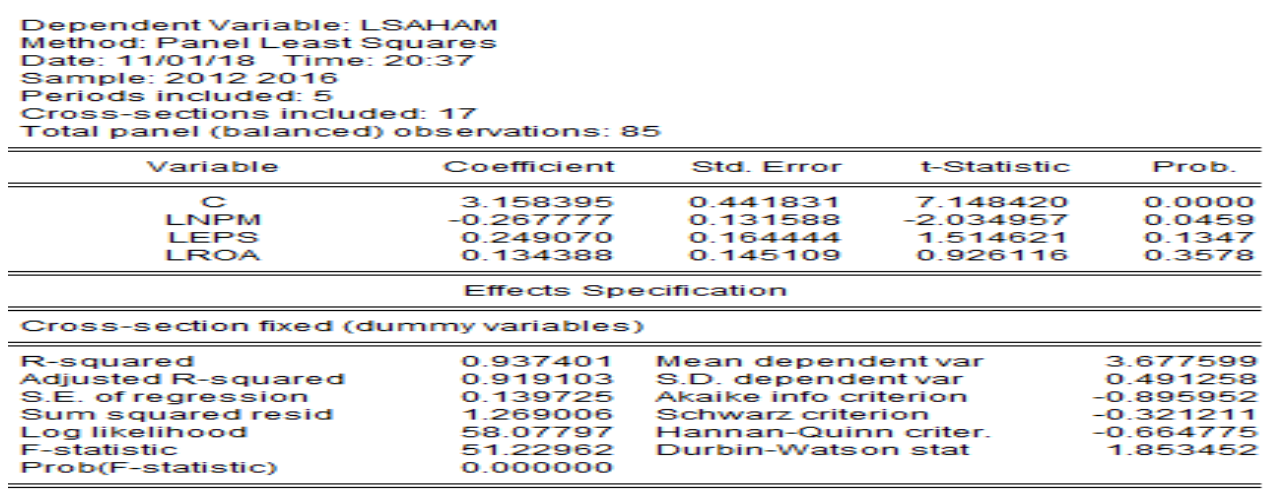

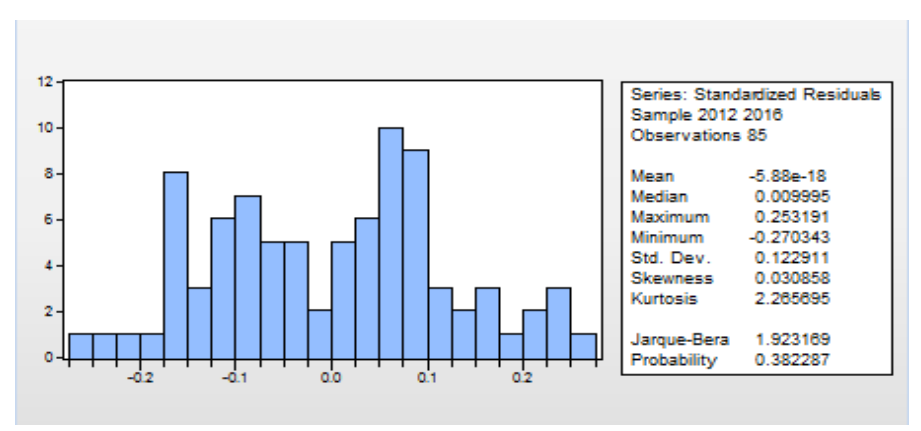

Dari hasil tabel diatas, maka didapat hasil probabilitas Jarque-bera sebesar $0.38>$ 0.05. Maka dapat ditarik kesimpulan bahwa dengan tingkat keyakinan $95 \%$ residual data terdistribusi secara normal. 
- $\quad$ Uji Regresi Berganda

Untuk mengetahui pengaruh variabel-variabel tersebut, maka dilakukan uji regresi menggunakan Eviews 8.0. Berikut adalah tabel hasil pengujian tersebut:

Berdasarkan tabel di atas, maka dapat disimpulkan bahwa.

- Hipotesis 1

Probabilitas NPM terhadap saham adalah 0.04 (lebih kecil daripada nilai signifikansi signifikansi $(\alpha)$ sebesar 5\%) maka hipotesis 1 ditolak. Artinya, terdapat pengaruh signifikan antara NPM terhadap harga saham properti secara parsial. Hasil ini konsisten dengan penelitian yang dilakukan oleh Darmawansyach (2012) namun bertentangan dengan Anisma (2012). Menurut Darmawansyach (2012), hal ini dikarenakan kekuatan perusahaan dalam melakukan ekspansi sehingga dapat meyakinkan investor untuk terus berinvestasi.

- Hipotesis 2

Probabilitas EPS terhadap saham adalah 0.13 (lebih besar daripada nilai signifikansi signifikansi $(\alpha)$ sebesar 5\%) maka hipotesis 2 diterima. Artinya, tidak terdapat pengaruh signifikan antara EPS terhadap harga saham properti secara parsial. Hasil ini konsisten dengan penelitian yang dilakukan oleh Anwar (2009), namun bertentangan dengan penelitian yang dilakukan oleh Jaenudin (2012).Menurut Hanafi dan Halim (2000; yang dikutip oleh Meythi, En, dan Rusli, 2011), hal ini disebabkan oleh EPS memiliki kelemahan, dimana EPS dinilai tidak konsisten untuk pengukuran profitabilitas.

- Hipotesis 3

Probabilitas ROA terhadap saham adalah 0.35 (lebih besar daripada nilai signifikansi signifikansi $(\alpha)$ sebesar 5\%) maka hipotesis 3 diterima. Artinya tidak terdapat pengaruh signifikan antara ROA terhadap harga saham properti secara parsial. Hasil ini konsisten dengan penelititan yang dilakukan oleh Idawati dan Wahyudi (2015), namun bertentangan dengan penelitian yang dilakukan oleh Jaenudin (2012). Menurut Idawati dan Wahyudi (2015), hal ini terjadi akibat investor tidak terlalu tertarik dengan bagaimana suatu perusahaan menegendalikan asset mereka untuk keuntungan.

- Hipotesis 4

Dari tabel di atas, didapat nilai signifikansi uji F sebesar $0.0000<0.05$. Hal ini berarti bahwa NPM, EPS, dan ROA secara bersama-sama signifikan mempengaruhi harga saham properti pada periode 2012-2016 dengan tingkat keyakinan 95\%.

- Uji Koefisien Determinasi $\left(\mathrm{R}^{2}\right)$

Dari di atas, didapat nilai koefisien determinasi dalam penelitian ini sebesar 0.9191. Hal ini berarti bahwa variabel-variabel independen (Net Profit Margin (NPM), Earning Per Share (EPS), Return On Asset (ROA)) mempengaruhi variabel harga saham properti sebesar 91,91\%, dimana sisanya sebesar 8,09\% dipengaruhi oleh variabel diluar penelitian ini.

\section{Kesimpulan}

Kesimpulan dari penelitian ini adalah bahwa secara parsial, net profit margin (NPM) memiliki pengaruh negatif signifikan terhadap harga saham properti di BEI, sedangkan earning per share (EPS) dan return on asset (ROA) memiliki pengaruh tidak signifikan terhadap harga saham perusahaan properti di BEI. Secara bersama-sama, net profit margin (NPM), earning per share (EPS), dan return on asset (ROA) memiliki pengaruh signifikan terhadap harga saham perusahaan properti di BEI.

\section{Daftar Pustaka}

Anisma, Yuneita. (2012). Faktor-Faktor Yang Mempengaruhi Harga Saham Perusahaan Perbankan Yang Listing Di Bursa Efek Indonesia (BEI). Jurnal Sosial Ekonomi Pembangunan. Volume 2, Nomor 5. 
Anwar, Solichin. (2009). Pengaruh Faktor Fundamental Dan Risiko Sistematik Terhadap Harga Saham Perusahaan Sektor Pembiayaan Di BEI Tahun 2007-2008. Depok: Universitas Gunadarma.

Aulianisa, Fitri. (2013). Pengaruh Faktor Fundamental Dan Risikosistematik Terhadap Harga Saham Di Pasar Modal Syariah (Studi Empiris JII Di BEI Tahun 2007-2010). Yogyakarta: Universitas Islam Indonesia.

Darmawansyach, Budi. (2012). Analisis Pengaruh Faktor-Faktor Fundamental Terhadap Harga Pasar Saham Perusahaan Agrobisnis Di Bursa Efek Indonesia. Medan: Universitas Terbuka UPBJJ Medan.

Idawati, Wiwi, \& Wahyudi, Aditio. (2015). Effect Of Earning Per Shares (EPS) And Return On Asset (ROA) Against Share Price On Coal Mining Company Listed In Indonesia Stock Exchange. Journal of Resources Development and Management. Volume 7.

Jaenudin, Jeni. (2012). Analisis Pengaruh Rasio Profitabilitas Terhadap Harga Saham Pada Perusahaan LQ45 Di Bursa Efek Indonesia (BEI). Lampung: Universitas Lampung.

Junita, Silvi dan Khairani, Siti. (2013). Analisa Kinerja Perusahaan Dengan Menggunakan Rasio Keuangan Pada Perusahaan Telekomunikasi Yang Terdaftar Di Bursa Efek Indonesia. Palembang: Sekolah Tinggi Ilmu Ekonomi MDP.

Meythi, Tan Kwen En, \& Linda Rusli. (2011). Pengaruh Likuiditas Dan Profitabilitas Terhadap Harga Saham Perusahaan Manufaktur Yang Terdaftar Di Bursa Efek Indonesia. Bandung: Universitas Kristen Maranatha.

Novitasari, Istriyansah. (2013). Pengaruh Inflasi, Harga Minyak Mentah Indonesia, Dan Suku Bunga (BI Rate) Terhadap Indeks HArha Saham Gabungan (IHSG) (Data Per Bulan Periode 2006-2012). Malang: Universitas Brawijaya.

Prihantini, Ratna. (2009). Analisis Pengaruh Inflasi, Nilai Tukar, ROA, DER, Dan CR Terhadap Return Saham (Studi Kasus Industri Real Estate And Property Yang Terdaftar Di Bursa Efek Indonesia Periode 2003-2006). Semarang: Universitas Diponegoro.

Putri, Anggun Amelia Bahar \& Sampurno, R. Djoko. (2012). Analisis Pengaruh ROA, EPS, NPM, DER, Dan PBV Terhadap Return Saham (Studi Kasus Pada Industri Real Estate And Property Yang Terdaftar Di Bursa Efek Indonesia Periode 2007-2009). Diponegoro Business Review. Volume 1, Nomor 1.

Titman, Sheridan, Keown, Arthur J., \& Martin, John D. (2011). Financial Management: Principal And Applications. Eleventh Edition. Boston, U.S.A: Pearson. 
